\title{
Analisis Kelayakan Finansial Selada Keriting dengan Sistem Hidroponik (Studi Kasus PT Cifa Indonesia)
}

\section{Financial Feasibility Analysis of Curly Lettuce using Hydroponics (Case Study PT Cifa Indonesia)}

\author{
Doni Sahat Tua Manalu'*, Lavyna Br Bangun ${ }^{2}$ \\ ${ }^{1}$ Dosen Politeknik Agroindustri, J1. Margamulya No.27 Ciasem, Kec. Ciasem, Kabupaten Subang, Jawa Barat, Indonesia \\ ${ }^{2}$ Mahasiswa Politeknik Agroindustri, Jl. Margamulya No.27 Ciasem, Kec. Ciasem, Kabupaten Subang, Jawa Barat, Indonesia \\ "email: manaludoni@gmail.com
}

I N F O A R T I K E L

Sejarah artikel:

Dikirim 13 Agustus 2020

Direvisi 05 September 2020

Diterima 30 Oktober 2020

Terbit 31 Oktober 2020

\section{Kata kunci:}

Hidroponik

Kelayakan finansial

Selada keriting

\section{Keywords:}

Hydroponics

Feasibility

Curly lettuce

\section{A B S T R A K}

Sistem tanam hidroponik merupakan salah satu alternatif untuk meningkatkan produktivitas hasil tanaman terutama di lahan sempit. PT Cifa Indonesia merupakan perusahaan bergerak di bidang pertanian yang membudiayakan selada pada sistem hidroponik. Analisis finansial membahas tentang layak atau tidaknya bisnis yang dijalankan. Tujuan dari penelitian ini adalah menganalisis kelayakan finansial selada keriting dengan sistem hidroponik pada PT. Cifa Indonesia Kabupaten Bogor. Penelitian dilaksanakan di PT. Cifa Indonesia, pemilihan lokasi penelitian dilakukan secara purposive. Jenis data yang digunakan pada penelitian ini adalah data primer dan sekunder. Pengumpulan data primer dilakukan dengan identifikasi langsung ke lapang dan wawancara. Selanjutnya, data sekunder diperoleh dengan melakukan studi literatur. Metode analisis pada aspek finansial dalam kajian pengembangan bisnis ini dikaji melalui analisis kelayakan usaha berdasarkan analisis analisis laba rugi, analisis arus kas (cashflow) dan analisis switching value. Berdasarkan hasil analisis finansial, budidaya selada keriting di PT. Cifa Indonesia telah memenuhi kriteria investasi meliputi NPV yang dihasilkan lebih besar dari nol yaitu sebesar Rp. 33.478.083, IRR lebih besar dari tingkat suku bunga yang digunakan yaitu sebesar 52\%, Net B/C yang dihasilkan lebih besar dari satu yaitu sebesar 5,56 , dan berdasarkan perhitungan payback period menghasilkan waktu pengembalian selama 4 tahun 5 bulan. Dengan demikian berdasarkan analisis finansial yang dilakukan pada budidaya selada keriting di PT. Cifa Indonesia adalah layak untuk dijalankan.

\section{A $B S T R A C T$}

The hydroponic planting system is an alternative to changing the planting system from a conventional to a hydroponic planting system that can be used to increase crop productivity. PT Cifa Indonesia is a company engaged in agriculture with hydroponic systems and production of lettuce. Financial analysis is an analysis that discusses the feasibility of a business being run. The purpose of this study was to analyze the financial feasibility of curly lettuce with the hydroponic system. The research method used purposively because using hydroponics to produce of lectuce. The types of data used in this study were primary and secondary data. Primary data collection methods were carried out by direct identification in the field and interviews. Secondary data were obtained by conducting literature studies. The method of analysis on the financial aspect in this business development study was examined through business feasibility analysis based on profit and loss analysis, cash flow analysis and switching value analysis. Based on the results of financial analysis, curly lettuce cultivation at PT. Cifa Indonesia had met the investment criteria including the resulting NPV greater than zero, at Rp. $33,478,083$, the IRR is greater than the interest rate used, at 52\%, the resulting Net $B / C$ is greater than one, namely 5.56, and based on the calculation of the payback period the payback period is 4 years and 5 months. Thus based on the financial analysis carried out on curly lettuce cultivation at PT. Cifa Indonesia is feasible. 


\section{PENDAHULUAN}

Meningkatnya jumlah penduduk Indonesia setiap tahunnya mempengaruhi peningkatan permintaan jumlah produksi hortikultura secara nasional. Di sisi lain, terjadinya penurunan jumlah produksi sayuran semusim disebabkan oleh berkurangnya lahan tanam dikarenakan alih fungsi lahan, lahan pertanian semakin sempit disebabkan oleh perkembangan industri semakin maju dengan pesat, perkembangan tersebut banyak yang menggeser lahan pertanian terlebih di daerah perkotaan. Padahal kebutuhan akan hasil pertanian semakin meningkat seiring dengan meningkatnya jumlah penduduk, oleh karena itu perlu dipirkirkan jalan keluar untuk mengatasi kondisi tersebut (Karsono et al, 2002).

Sistem tanam hidroponik merupakan salah satu alternatif untuk merubah sistem tanam dari sistem tanam konvensional menjadi sistem tanam hidroponik yang dapat digunakan untuk meningkatkan produktivitas hasil tanaman terutama di lahan sempit. Menurut Kaleka (2019) hidroponik sistem NFT merupakan salah satu sistem budidaya tanaman tanpa tanah yang sudah dikembangkan sejak tahun 1960 dan berkembang secara komersial pada tahun 1970. Penemu dan pelopor hidroponik sistem NFT adalah A. J. Cooper. Beliau adalah salah seorang ilmuwan di Glasshouse Crops Research, Inggris. Pada hidroponik sistem NFT, unsur hara yang dilarutkan dalam air, dialirkan melalui instalasi hidroponik, bisa dari pipa paralon atau talang, dalam aliran yang dangkal dengan ketebalan arus sekitar 4-5 mm (kedalaman tersebut tidak mutlak).

Tanaman yang disemaikan menggunakan rockwool, diletakkan dalam netpot atau dalam wadah tanam agar akar tanaman dapat terjuntai masuk dalam aliran air yang mengandung unsur hara tipis pada talang atau pipa paralon yang menjadi bedengan atau tempat berdirinya tanaman. Pada tanaman yang baru ditanam, akarnya belum dapat menjangkau aliran air, namun tanaman tersebut dapat memperoleh unsur hara melalui sumbu yang dipasang pada bagian bawah net pot. Ketika tanaman terus bertumbuh, sebagian akar tanaman terendam dalam air tetapi tetap memungkinkan akar tersebut dapat menyerap oksigen dari udara. Dengan demikian unsur hara dapat diserap secara terus menerus oleh akar tanaman karena ada aliran air yang terus bersirkulasi tanpa henti dari tandon penampung. Air dari tandon penampung dinaikkan menggunakan pompa listrik. Wibowo (2013) menyatakan bahwa beberapa keunggulan yang diperoleh dari sistem hidroponik antara lain adalah mudah dalam pengendalian nutrisi, relatif tidak menghasilkan nutrisi polusi nutrisi ke lingkungan, memberikan hasil yang lebih banyak, bebas dari tumbuhan pengganggu, steril dan bersih. Selain itu menurut Herwibowo dan Budiana (2014) sistem hidroponik dapat mempermudah waktu panen, penggunaan air dan unsur hara yang terukur dan kualitas, kuantitas dan kontinuitas yang terjamin.

Semakin meningkatnya kepedulian masyarakat terhadap kesehatan dan pencemaran lingkungan sehingga masyarakat semakin sadar dalam memilih makanan yang sehat dan memilih sayuran non pestisida. Hal ini menyebabkan permintaan sayuran non pestisida semakin meningkat dan menjadi peluang pasar yang besar bagi petani hidroponik. Peluang pasar sayuran non pestisida bukan hanya datang dari rumah tangga, namun juga dari restoran dan hotel. Pengembangan Sistem hidroponik memiliki prospek ekonomi yang cukup cerah dan dapat memberikan suatu lingkungan pertumbuhan yang lebih terkontrol.

Salah satu tanaman yang dapat tumbuh dengan baik dengan sistem hidroponik adalah selada.Potensi pasar yang masih relatif besar menjadikan selada banyak dikembangkan oleh petani hidroponik baik berskala kecil maupun besar. PT Cifa Indonesia merupakan perusahaan yang bergerak dalam bidang pertanian dengan sistem hidroponik dan membudidayakan selada. Dari sisi konsumen, peningkatan kesadaran masyarakat akan pentingnya mengkonsumsi sayuran menjadi salah satu peluang bagi PT Cifa Indonesia karena dapat menjadi solusi diversifikasi pangan di Indonesia. Diversifikasi konsumsi merupakan upaya penganekaragaman pola konsumsi masyarakat, sedangkan diversifikasi produksi merupakan upaya penganekaragaman kegiatan usahatani dan hasil-hasil produksi pertanian (Muchilisin, 2013, dan Rifaldi dan Ismail, 2019).

Analisis finansial merupakan analisis yang membahas tentang layak atau tidaknya bisnis yang dijalankan, dalam upaya mengetahui perkiraan pendanaan dan aliran kas. Analisis ini membandingkan antara biaya dan manfaat untuk menentukan apakah suatu bisnis akan menguntungkan selama umur bisnis tersebut (Husnan dan Muhammad, 2000). Berdasarkan latarbelakang yang telah diuraikan maka yang menjadi tujuan dari penelitian ini adalah menganalisis kelayakan finansial selada keriting dengan sistem hidroponik pada PT. Cifa Indonesia Kabupaten Bogor. 


\section{METODE}

Penelitian Penelitian dilaksanakan di PT. Cifa Indonesia, pemilihan lokasi penelitian dilakukan secara purposive karena PT. Cifa Indonesia adalah salah satu perusahaan yang memproduksi selada keriting menggunakan hidroponik. Jenis data yang digunakan pada penelitian ini adalah data primer dan sekunder. Metode pengumpulan data primer dilakukan dengan identifikasi langsung ke lapang dan wawancara. Selanjutnya, data sekunder diperoleh dengan melakukan studi literatur.

Metode analisis pada aspek finansial dalam kajian pengembangan bisnis ini dikaji melalui analisis kelayakan usaha berdasarkan analisis analisis laba rugi, analisis arus kas (cashflow) dan analisis switching value.

\subsection{Laporan Laba Rugi Bisnis}

Langkah penting yang dilakukan dalam pengelolaan bisnis adalah menyusun laporan laba/rugi, yang berisi tentang total penerimaan pengeluaran dan kondisi keuntungan yang diperoleh suatu perusahaan dalam satu tahun akuntansi atau produksi. Laporan laba/rugi menggambarkan kinerja perusahaan dalam upaya mencapai tujuannya selama periode tertentu. Laporan laba rugi merupakan ringkasan dari empat jenis suatu bisnis (Nurmalina et al.,. 2018 dan Freddy, 2014). Adapun ke empat jenis kegiatan tersebut adalah:

a. Pendapatan dari penjualan produk barang dan jasa.

b. Beban produksi untuk mendapatkan barang atau jasa yang akan dijual.

c. Beban yang timbul dalam memasarkan dan mendistribusikan produk atau jasa pada konsumen serta yang berkaitan dengan beban administratif dan operasional.

d. Beban keuangan dalam menjalankan bisnis, contohnya bunga yang dibayarkan pada bank/kreditur, penyusutan, dan lainnya.

$$
\pi=\mathrm{TR}-\mathrm{TC}
$$

Keterangan: $\pi=$ Keuntungan

TR $=$ Total Penerimaan

$\mathrm{TC}=$ Total Pengeluaran

\subsection{Proyeksi Arus Kas}

Cash flow merupakan aktivitas keuangan yang mempengaruhi posisi atau kondisi kas pada suatu periode tertentu. Cash flow menggambarkan arus kas penerimaan (inflow) pada parusahaan dan arus kas pengeluaran (outflow) pada perusahaan. Menurut Kasmir dan Jakfar (2003) arus kas adalah jumlah uang yang masuk dan keluar dalam suatu perusahaan dari investasi dilakukan sampai dengan berakhirnya investasi tersebut. Cash flow menjadi bagian bagian terpenting yang harus diperhatikan oleh pihak manajemen, investor, konsultan dan stakeholder lainnya untuk memperhitungkan kelayakan berdasarkan kriteria investasi yang ada (Nurmalina et al., 2018 dan Ibrahim, 2009 ). Kriteria investasi yang dapat digunakan untuk mempertimbangkan kelayakan suatu usaha yaitu: NPV (Net Present Value), Gross B/C (Gross Benefit Cost Ratio), Net B/C (Net Benefit Cost Ratio), IRR (Internal Rate of Return), dan PP (Payback Period), uraian selengkapanya sebagai berikut:

\subsubsection{NPV (Net Present Value)}

NPV (Net Present Value) adalah selisih antara total present value manfaat dengan total present value biaya atau jumah present value dari manfaat bersih tambahan selama umur bisnis. Nilai yang dihasilkan oleh perhitungan NPV adalah dalam satuan mata uang (Rp). Suatu bisnis dapat dinyatakan layak jika jumlah seluruh manfaat yang diterimanya melebihi biaya yang dikeluarkan. Selisih antara manfaat dan biaya disebut dengan manfaat bersih atau arus kas bersih (Nurmalina et al. 2018). Secara matematis NPV dapat dirumuskan sebagai berikut.

$$
\mathrm{NPV}=\sum_{i=0 / 1}^{n} \frac{B t-C t}{(1+i)^{n}}
$$

Keterangan: $\mathrm{Bt}=$ Manfaat pada tahun ke-t

$\mathrm{Ct}=$ Biaya pada tahun ke-t

$\mathrm{T}=$ Tahun kegiatan bisnis

$\mathrm{i}$ = Tingkat Discount Rate (\%) 
Suatu bisnis dinyatakan layak jika NPV lebih besar dari 0 (NPV >0) yang artinya bisnis menguntungkan atau memberikan manfaat. Jika suatu bisnis memiliki nilai NPV kurang dari 0 $(\mathrm{NPV}<0)$ artinya bisnis tersebut tidak layak untuk dijalankan. Suatu bisnis berada pada titik impas ketika nilai NPV sama dengan 0 (NPV=0). Pada titik ini, suatu bisnis tidak mengalami kerugian ataupun keuntungan.

\subsubsection{Gross B/C (Gross Benefit Cost Ratio)}

Gross B/C ratio merupakan kriteria kelayakan lain yang biasa digunakan dalam analisis bisnis. Kriteria ini akan menggambarkan pengaruh dari adanya tambahan biaya terhadap tambahan manfaat yang diterima. Kriteria ini memberi pedoman bahwa bisnis dinyatakan layak untuk dijalankan apabila Gross B/C lebih besar dari 1 dan suatu bisnis dinyatakan tidak layak apabila Gross B/C kurang dari 1 (Nurmalina et al., 2018). Secara matematis Gross B/C dapat dirumuskan sebagai berikut:

$$
\text { Gross } B / C=\frac{\sum_{t=0 / 4}^{n} \frac{B t}{(1+1)^{2}}}{\sum_{t=0 / 1}^{n} \frac{C t}{(1+1+1)^{2}}}
$$

Keterangan: $\mathrm{Bt}=$ Manfaat pada tahun ke-t

$\mathrm{Ct}=$ Biaya pada tahun ke-t

$\mathrm{T}=$ Tahun kegiatan bisnis

$\mathrm{i}=$ Tingkat Discount Rate $(\%)$

Jika Gross B/C ratio > 1 maka bisnis layak dijalankan

Jika Gross B/C ratio < 1 maka bisnis tidak layak dijalankan

\subsubsection{Net B/C (Net Benefit Cost Ratio)}

Net $B / C$ ratio adalah rasio antara manfaat bersih yang bernilai positif dengan manfaat bersih yang bernilai negatif. Dengan kata lain, manfaat bersih yang menguntungkan bisnis yang dihasilkan terhadap setiap satu satuan kerugian dari bisnis tersebut. Suatu bisnis dapat dikatakan layak apabila nilai $N e t B / C$ lebih besar dari satu dan bisnis dikatakan tidak layak apabila nilai $N e t B / C$ kurang dari satu (Nurmalina et al., 2018). Secara matematis dapat dinyatakan sebaga berikuti:

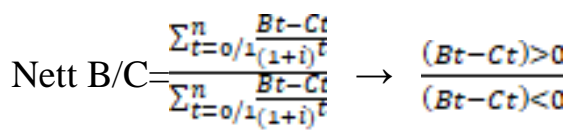

Keterangan: $\mathrm{Bt}=$ Manfaat pada tahun ke-t

$\mathrm{Ct}=$ Biaya pada tahun ke-t

$\mathrm{T}=$ Tahun kegiatan bisnis

$\mathrm{i}=$ Tingkat Discount Rate $(\%)$

Jika Net $B / C$ ratio $>1$ maka bisnis layak untuk dijalankan

Jika Net $B / C$ ratio $<1$ maka bisnis tidak layak untuk dijalankan

\subsubsection{IRR (Internal Rate of Return)}

Kelayakan bisnis juga dinilai dari seberapa besar pengembalian bisnis terhadap investasi yang ditanamkan dengan mengukur besaran IRR. IRR (Internal Rate of Return) adalah tingkat discount rate (DR) yang menghasilkan nilai NPV sama dengan nol. Besaran yang dihasilkan dari perhitungan ini adalah dalam satuan persentase (\%). Bisnis dapat dikatakan layak jika IRR-nya lebih besar dari opportunity cost of capital-nya (DR) (Nurmalina et al., 2018 dan Danang, 2014). Berikut merupakan rumus IRR:

$$
\operatorname{IRR}=\mathrm{i}_{1}+\frac{N P V 1}{\text { NPV1-NPV2 }} \mathrm{X}\left(\mathrm{i}_{2}-\mathrm{i}_{1}\right)
$$

$$
\begin{array}{cl}
\text { Keterangan: } \mathrm{NPV}_{1} & =\mathrm{NPV} \text { posiif }(\mathrm{Rp}) \\
\mathrm{NPV}_{2} & =\mathrm{NPV} \text { negative }(\mathrm{Rp}) \\
\mathrm{i}_{1} & =\text { Interest/Discount rate NPV positif }(\%) \\
\mathrm{i}_{1} & =\text { Interest/Discount rate NPV positif }(\%)
\end{array}
$$




\subsubsection{PP (Payback Period)}

Payback period (PP) merupakan penilaian pengembalian investasi suatu usaha. Metode payback period mencoba mengukur seberapa cepat investasi bisa Kembali. Bisnis yang payback period-nya singkat atau cepat pengembaliannya termasuk kemungkinan besar akan dipilih. Secara matematis PP dapat dirumuskan sebagai berikut:

$$
\text { Payback period }=\frac{I}{A b}
$$

Keterangan: I = Besarnya biaya investasi yang diperlukan

$\mathrm{Ab} \quad=$ Manfaat bersih yang dapat diperoleh pada setiap tahunnya

\subsubsection{Analisis Switching Value}

Analisis switching value atau nilai pengganti merupakan perhitungan untuk mengukur perubahan maksimum dari perubahan suatu komponen inflow (penurunan harga output, penurunan produksi) atau perubahan komponen outflow (peningkatan harga input, peningkatan biaya produksi), yang masih dapat ditoleransi agar bisnis masih tetap layak. Perhitungan ini bertujuan untuk mengetahui sampai titik berapa peningkatan ataupun penurunan suatu komponen dapat mengakibatkan perubahan dalam kriteria investasi. Perhitungan analisis ini mengacu kepada berapa besar perubahan yang terjadi pada setiap komponen outflow ataupun inflow sampai dengan NPV sama dengan nol (NPV=0) (Nurmalina et al., 2018).

\section{HASIL DAN PEMBAHASAN}

\subsection{Budidaya dan Pascapanen Selada Keriting}

Kegiatan produksi selada keriting menggunakan sistem hidroponik akan membantu proses pemeliharaanya. Selain itu, penggunaan system hidroponik juga memudahkan pembersihan sehingga serangan hama penyakit dan dapat diatasi dan dapat meningkatkan produksi usahatani sayuran hidroponik. Pada penelitian ini system hidroponik yang digunakan adalah sistem tertutup (Roidah, 2014). Sistem tertutup adalah sistem yang menggunakan air atau larutan nutrisi yang dapat dimanfaatkan kembali setelah digunakan. Sistem tertutup yang digunakan pada greenhouse adalah sistem hidroponik Nutrient Film Technique (NFT) menggunakan media tanam pipa PVC yang dialiri nutrisi. Tahapan pertama yang dilakukan adalah persemaian. Persemaian merupakan kegiatan pertama yang dilakukan dalam memproduksi selada keriting. Berbeda dengan penelitian Susila dan Koerniawati, (2004) yang menggunakan media rockwool.

Tahap-tahap dalam melakukan kegiatan persemaian yang pertama adalah menyiapkan media tanam berupa rockwool dengan memotong rockwool dan disusun dalam tray, setelah itu rockwool dibasahi dengan air sehingga lembab. Setelah media tanam siap kemudian benih selada keriting disemai dua biji perlubangnya selanjutnya tray diletakkan pada tempat tertutup yang terletak di luar greenhouse selama \pm 2 hari. Penyiapanan benih di tempat yang tertutup untuk proses etiolasi benih, sehingga dapat memacu percepatan pertumbuhan tanaman. Selanjutnya tray tersebut diletakkan di tempat terbuka yaitu di dalam greenhouse.

Di green house tanaman mendapatkan fertigasi hanya pada pagi hari dan sore hari dan hanya sebatas sampai media tanamnya jenuh air untuk menghindari serangan penyakit. Setelah bibit berumur 15 hari, kemudian bibit siap dipindahtanamkan ke meja peremajaan, caranya dengan memisahkan setiap bibit dan memasukannya ke dalam netpot. Setelah itu, bibit tersebut ditempatkan di meja peremajaan. Jarak tanam antar bibit selada keriting di meja peremajaan adalah $2 \mathrm{~cm} \times 2 \mathrm{~cm}$. Lama bibit ditempatkan di meja peremajaan adalah 7 hari, sampai selada tumbuh daun muda sebanyak 3-5 helai daun selada keriting dan selanjutnya dipindahkan kemeja produksi. Dilakukan pindah tanam dari meja peremajaan ke meja produksi. Jarak tanam antar selada keriting di meja produksi adalah $15 \mathrm{~cm} \mathrm{x}$ $15 \mathrm{~cm}$. Jarak tanam di meja produksi lebih lebar dari jarak tanam di meja peremajaan karena selada keriting diharapkan dapat memiliki daun selada yang lebih lebar, di green house meja produksi selada keriting pengendalian hama penyakit dilakukan secara manual dengan cara membersihkan gulma yang tumbuh dibawah meja produksi dan langsung membuang tanaman yang terkena hama penyakit sampai selada keriting siap untuk dipanen.

Rawan (2016) menyatakan perawatan lain pada selada keriting berupa pengecekan $\mathrm{pH}$ air dan juga kadar nutrisi pada tanaman, pengecekan dilakukan pada pagi hari atau pada saat setelah turun hujan, $\mathrm{pH}$ yang sesuai untuk tanaman selada adalah antara 6-7, sedangkan kebutuhan nutrisi untuk 
selada adalah 560-840 ppm. Pada keadaan tersebut $\mathrm{pH}$ air dan juga kadar nutrisi lebih cepat berubah. Ketika $\mathrm{pH}$ berubah bisa mengontrolnya dengan menggunakan $\mathrm{pH}$ down untuk menurunkan $\mathrm{pH}$, dan menggunakan $\mathrm{pH}$ up untuk menaikan $\mathrm{pH}$, kemudian apabila kadar nutrisi berubah dilakukan pengontrolan nutrisi, apabila kadar nutrisi berkurang, ditambah kadar nutrisi ke dalam bak penampung nutrisi yang ada.

Panen selada keriting dilakukan dengan cara manual yaitu tanaman langsung dicabut pada bagian netpotnya secara hati-hati dan dibawa ke ruang packing, lama waktu panen yaitu 2-3 minggu. Eprianda (2017) menyatakan memproduksi tanaman selada selama \pm 45 hari. Proses selada keriting dimulai dari penyemaian di ruang gelap selama 2-4 hari, perawatan tanaman muda (nursery) dan perawatan tanaman siap panen selama 13-15 hari.

Pascapanen merupakan proses lanjutan yang dilakukan pada hasil produksi untuk memaksimalkan kualitas hasil produksi. Kegiatan pascapanen meliputi perompesan selada keriting. Perompesan daun dilakukan dengan cara memisahkan netpot dari tanaman selada, kemudian membuang daun busuk dan daun muda sebanyak 2 sampai 5 helai daun, tetapi tergantung pada keadan selada keriting, helai daun yang dibuang pada bagian luar tanaman selada keriting. Akar panjang juga dibuang agar tanaman selada terlihat rapih dan bersih. Selanjutnya pengemasan, sayuran dimasukan ke dalam plastik dengan berat 250 gram per pack, akar selada keriting diratakan kemudian pada bagian bawah plastik dililit dua kali menggunakan selotip dan pada bagian atas plastik dibiarkan terbuka, pengemasan produk seperti ini menghasilkan bentuk produk seperti bucket bunga agar terlihat menarik. Selain itu, bentuk daun selada keriting akan terjaga saat proses pengangkutan ke outlet dan distribution centre (DC).

\subsection{Perencanaan Finansial}

Perencanaan finansial yang digunakan pada penelitian ini adalah menggunakan analisis cashflow yang akan menghitung pengaruh waktu terhadap nilai uang secara umur ekonomis sebuah kegiatan usaha. Asumsi-asumsi dasar yang digunakan dalam penyusunan analisis cashflow budidaya selada keriting di PT. Cifa Indonesia adalah: Umur proyeksi budidaya selada keriting ditetapkan selama 10 tahun berdasarkan umur ekonomis peralatan yaitu green house.

1. Tingkat kegagalan (mortalitas) sebanyak 5\%.

2. Modal yang digunakan pada budidaya selada keriting menggunakan modal sendiri dari pemilik perusahaan PT. Cifa Indonesia tanpa bantuan dari pihak manapun.

3. Biaya reinvestasi disesuaikan dengan umur ekonomis peralatan. Reinvestasi dilakukan apabila umur ekonomis peralatan yang sudah habis.

4. Menggunakan perhitungan common cost pada komponen biaya yang digunakan bersamaan dengan unit bisnis/produk lain sebesar 5,71\% .

5. Tingkat suku bunga yang digunakan berdasarkan tingkat suku bunga deposito rata-rata bank di Indonesia pada tahun 2020 yaitu sebesar 6,5\%.

6. Pajak penghasilan yang digunakan yaitu $0,5 \%$ berdasarkan Peraturan Pemerintah (PP) Republik Indonesia No. 23 Tahun 2018.

\subsection{Kelayakan Finansial}

Kelayakan finansial dalam budidaya selada keriting dengan hidroponik di PT. Cifa Indonesia terdapat beberapa aspek yang dikaji yaitu arus penerimaan (inflow), arus pengeluaran (outflow), analisis laba rugi, analisis kelayakan usaha dan analisis nilai pengganti (switching value).

\subsubsection{Arus Penerimaan}

Arus penerimaan merupakan pemasukan dalam suatu bisnis mulai dari pada saat permulaan bisnis maupun selama bisnis berlangsung. Penerimaan yang dihasilkan melalui budidaya selada keriting berasal dari hasil penjualan produk. PT. Cifa Indonesia memperoleh total penerimaan sebesar Rp. 114.628.800 pada tahun pertama, Rp. 156.512.400 pada tahun kedua, ke empat, ke enam, ke delapan dan ke sepuluh, Rp. 113.827,200 pada tahun ke tiga, ke lima, ke tujuh dan ke sembilan.

\subsubsection{Arus Pengeluaran}

Arus pengeluaran adalah keseluruhan biaya yang dikeluarkan dalam menjalankan suatu usaha. Biaya dalam budidaya selada keriting dengan system hidroponik terbagi menjadi dua, yaitu biaya investasi dan biaya operasional. 
a. Biaya investasi

Biaya investasi adalah biaya yang dikeluarkan pada awal kegiatan usaha untuk memperoleh beberapa kali manfaat pada tahun berikutnya sampai umur ekonomis kegiatan bisnis itu tidak menguntungkan lagi. Total biaya investasi yang dibutuhkan dalam melaksanakan usaha pada tahun pertama sebesar Rp. 35.242.098 biaya tersebut berfungsi untuk memenuhi kebutuhan sarana dan prasarana yang diperlukan untuk budidaya selada keriting.

b. Biaya operasional

Biaya operasional merupakan biaya yang harus dikeluarkan dalam rangka memenuhi input produksi agar kegiatan produksi berjalan lancar. Biaya operasional terdiri dari biaya tetap dan variabel. Kebutuhan biaya operasional ditaksir berdasarkan rencana produksi dan besarnya ditentukan dari kebutuhan yang akan dipenuhi. Biaya tetap adalah biaya yang dikeluarkan dengan jumlah tetap setiap periode. Biaya yang dikeluarkan tidak mempengaruhi banyaknya jumlah produksi. Biaya tetap yang akan dikeluarkan pada budidaya selada keriting meliputi gaji karyawan, sewa lahan, pajak bumi dan bangunan, biaya listrik, air dan lain-lain. Biaya tetap yang dikeluarkan yaitu sebesar Rp. 94.516.626 pada tahun pertama dan Rp. 97.289.331 pada tahun ke dua hingga ke sepuluh. Sedangkan biaya variabel adalah biaya yang dikeluarkan pada saat proses produksi dalam suatu periode tertentu yang jumlahnya bergantung pada kuantitas produk yang diproduksi.

\subsubsection{Analisis Laba Rugi}

Analisis laba rugi mengukur keberhasilan operasional perusahaan selama jangka waktu tertentu. Laporan laba rugi budidaya selada keriting mengalami penerimaan bersih bernilai positif atau untung. Proyeksi laba rugi budidaya selada keriting di PT. Cifa Indonesia dapat dilihat pada Tabel 1.

Tabel 1. Hasil perhitungan analisis laba rugi budidaya selada keriting di PT. Cifa Indonesia

\begin{tabular}{crrr}
\hline Tahun & Laba bersih sebelum pajak & Pajak (0.5\%) & Laba bersih setelah pajak \\
\hline 1 & Rp. 7.943 .713 & - & Rp. 7.943 .713 \\
$2,4,6,8,10$ & Rp. 40.365 .308 & Rp. 2.018 .315 & Rp. 38.347 .993 \\
$3,5,7,9$ & Rp. 426.588 & Rp. 21.329 & Rp. 405.258 \\
\hline
\end{tabular}

\subsubsection{Analisis Cashflow}

Analisis yang digunakan dalam rencana pendirian unit bisnis ini adalah analisis cashflow atau analisis arus kas. Analisis cashflow disusun untuk menunjukkan perubahan kas selama satu periode tertentu sehingga membantu perusahaan untuk mengetahui kondisi keuangan perusahaan. Analisis kelayakan budidaya selada keriting menggunakan NPV, IRR, Net B/C, dan payback period. Hasil perhitungan kriteria kelayakan usaha dengan analisis cashflow dapat dilihat pada Tabel 2.

Tabel 2. Hasil perhitungan analisis cashflow budidaya selada keriting di PT. Cifa Indonesia

\begin{tabular}{cccc}
\hline Kriteria investasi & Kriteria kelayakan & Hasil & Keterangan \\
\hline NPV & NPV $>0$ & Rp. 70.071 .929 & Layak \\
IRR & IRR $>$ DR $(6,5 \%)$ & $56 \%$ & Layak \\
Net B/C & Net B/C $>1$ & 4,21 & Layak \\
Payback Period & PP $<$ Umur Bisnis 10 tahun & 4,23 & Layak \\
\hline
\end{tabular}

a. $\quad$ Net Present Value (NPV)

NPV budidaya selada keriting di PT. Cifa Indonesia sebesar Rp70.071.929,00 artinya jumlah manfaat bersih yang diperoleh selama umur bisnis 10 tahun sebesar Rp. 70.071 .929 sehingga nilai NPV > 0, maka bisnis layak dijalankan.

b. Internal Rate Ratio (IRR)

IRR pada budidaya selada keriting di PT. Cifa Indonesia. sebesar $56 \%$ yang memiliki interpretasi bahwa usaha tersebut memberikan keuntungan sebesar $56 \%$ dari investasi yang ditanamkan. Artinya IRR $>\mathrm{DR}=56 \%>6,5 \%$, maka bisnis ini layak dijalankan.

c. Net Benefit Cost Ratio (Net B/C)

Net B/C budidaya selada keriting di PT. Cifa Indonesia sebesar 4,21 nilai tersebut memliki interpretasi bahwa setiap Rp.1 biaya yang dikeluarkan menghasilkan manfaat bersih sebesar Rp. 4,21. Artinya Net B/C > 1, maka bisnis layak dijalankan. 
d. $\quad$ Payback Period

Budidaya selada keriting di PT. Cifa Indonesia memiliki payback period 4,23 yang artinya modal investasi dapat kembali dalam kurun waktu 4 tahun 3 bulan dan layak untuk dijalankan karena lebih kecil dari umur bisnis yaitu 10 tahun.

\subsubsection{Analisis Switching Value}

Switching value digunakan untuk mengetahui ambang batas maksimal peningkatan atau penurunan suatu variabel yang dapat mengakibatkan perubahan dalam kriteria investasi menjadi tidak untung dan tidak rugi. Batas toleransi dilihat dari perubahan maksimum dari suatu komponen inflow (penurunan penjualan) atau perubahan outflow (kenaikan biaya produksi). Perhitungan switching value pada budidaya selada keriting di PT. Cifa Indonesia berdasarkan analisis switching value terdapat pada Tabel 3.

Tabel 3. Hasil perhitungan analisis switching value budidaya selada keriting di PT. Cifa Indonesia.

\begin{tabular}{lcccc}
\hline \multicolumn{1}{c}{ Perubahan kondisi } & Perubahan (\%) & NPV & Net B/C & IRR(\%) \\
\hline Penurunan jumlah produksi & $9,42 \%$ & 0 & 2,57 & $11 \%$ \\
Kenaikan harga input (bibit) & $110,87 \%$ & 0 & 2,79 & $11 \%$ \\
\hline
\end{tabular}

Tabel 3 menjelaskan batas toleransi maksimum untuk penurunan jumlah produksi selada keriting sebesar 9,42\%. Selanjutnya, batas toleransi untuk kenaikan harga bibit sebesar 110,87\%. Keadaan tersebut terjadi saat kondisi nilai NPV sama dengan nol. Penurunan produksi ini dapat terjadi karena terserangnya tanaman oleh hama dan penyakit yang tidak ditanggulangi oleh perusahaan sehingga menyebabkan selada kering tidak dapat dijual, hal ini sesuai dengan penelitian Umikalsum (2019) dan Amalia dan Fitri (2020) bahwa petani perlu melakukan pencegahan atau penanggulangan hama sejak dini dengan menggunakan pestisida nabati agar tanaman sayur dapat aman dikonsumsi pada budidaya sayuran selada hidroponik. Titik kritis saat proses produksi yaitu saat pemeliharaan tanaman.

Apabila pengendalian hama dan penyakit tidak dilakukan dengan baik, maka akan menyebabkan sayuran rusak sehingga tidak dapat dipanen. Begitu juga dengan kenaikan harga input. Peningkatan harga input (benih) dipilih dalam analisis switching value karena merupakan komponen penting dalam produksi selada keriting. Dengan demikian perusahaan dikatakan sensitif terhadap penurunan jumlah produksi selada keriting dan tidak sesitif terhadap peningkatan harga input. Penentuan batas toleransi dimaksudkan agar bisnis tetap layak untuk dijalankan. Apabila perubahan yang terjadi melebihi batas toleransi, maka bisnis dapat dikatakan tidak layak dan perlu dilakukan evaluasi.

\section{KESIMPULAN DAN SARAN}

\subsection{Kesimpulan}

Karakteristik Berdasarkan hasil analisis finansial, budidaya selada keriting di PT. Cifa Indonesia telah memenuhi kriteria investasi meliputi NPV yang dihasilkan lebih besar dari nol yaitu sebesar Rp. 33.478.083, IRR lebih besar dari tingkat suku bunga yang digunakan yaitu sebesar 52\%, Net B/C yang dihasilkan lebih besar dari satu yaitu sebesar 5,56, dan berdasarkan perhitungan payback period menghasilkan waktu pengembalian selama 4 tahun 5 bulan. Dengan demikian berdasarkan analisis finansial yang dilakukan pada budidaya selada keriting di PT. Cifa Indonesia adalah layak untuk dijalankan.

\subsection{Saran}

Berdasarkan hasil analisis switching value sebaiknya terus mempertahankan variable-variable seperti jumlah produksi dan harga bibit, untuk dapat tidak mencapai ambang batas. Ambang batas yang harus dijaga oleh perusahaan masing-masing sebesar 9,42\% untuk kenaikan jumlah produksi dan $110,87 \%$ untuk kenaikan harga bibit. 


\section{DAFTAR PUSTAKA}

Amalia A.,F., \& Fitri, A. (2020). Analisis Usahatani Sayuran Selada Menggunakan Hidroponik Sederhana Pada Lahan Pekarangan. Mimbar Agribisnis. Jurnal Pemikiran Masyarakat Ilmiah Berwawasan Agribisnis, 6(2): 774-783.

Danang, S. (2014). Studi Kelayakan Bisnis. Edisi Pertama. Yogyakarta : CAPS (Center Of Academic Publishing Service).

Eprianda, D. (2017). Efesiensi Produksi dan Analisis Resiko Budidaya Selada Keriting Hijau dan Selada Romaine Hidroponik NFT (Nutrient Film Technique) di PT. XYZ, Provinsi Jawa Barat.

Freddy, R. (2014). Analisis SWOT Teknik Membedah Kasus Bisnis, PT.Gramedia. Jakarta.

Herwibowo, K., \& Budiana. (2014). Hidroponik Portable. Yogyakarta: Penebar Swadaya Grup.

Husnan, S., \& Muhammad, S. (2000). Studi Kelayakan Proyek. Yogyakarta: UUP STIM YKPN.

Ibrahim, Y. (2009). Studi Kelayakan Bisnis. Jakarta: Penebar Swadaya Grup.

Kaleka, N. (2019). Hidroponik Sistem NFT Sekala Rumah Tangga. Solo: Pustaka Baru.

Karsono, S., Sudarmodjo \& Sutiyoso, Y. (2002). Hidroponik: Skala Rumah Tangga. PT. Agro Media Pustaka. Jakarta.

Muchilisin, R. (2013). Pengertian, Klasifikasi dan Tingkat Produksi. Retrieved From http://www.kajianpustaka.com/2013/pengertian-klasifikasi-dan-tingkatan.html.

Nurmalina R., Sarianti T., \& Karyadi A. (2018). Studi Kelayakan Bisnis. Bogor (ID): IPB Press.

Rawan, K.,S. (2016). Pengaruh Media Tanam Pada Berbagai Konsentrasi Nutrisi Tumbuhan Terhadap Pertumbuhan dan Hasil Seledri Dengan Sistem Tanam Hidroponik NFT.

Rifaldi \& Ismail. (2019). Analisis Pendapatan Usahatani Hidroponik Matuari di Kelurahan Paniki Bawah Kota Manado. Retrieved From https://ejournal.unsrat.ac.id /index.php/agrirud/article/view/24440.

Roidah, I., S. (2014). Pemanfaatan Lahan Dengan Menggunakan Sistem Hidroponik. Jurnal Universitas Tulungagung Bonorowo Tahun, 1(2), 43-50.

Susila, A., D., Koerniawati, Y. (2004). Pengaruh Volume dan Jenis Media Tanam Pada Pertumbuhan dan Hasil Tanaman Selada (Lactuca sativa) Dalam Teknologi Hidroponik Sistem Terapung. Bul Agron. 32(3): 16-21.

Umikalsum, R., A. (2019). Analisis Usahatani Tanaman Selada Hidroponik Pada Kebun Eve's Veggies Hydroponics Kota Palembang. Societa. VIII-1:52-57.

Wibowo, Sapto, Arum A., S. (2013). Application of NFT Hydroponic of Culvatian of Pakcoy. Jurnal Penelitian Pertanian Terapan, 13 (3):159-167. 
[Halaman ini sengaja dikosongkan]

DOI: https://doi.org/10.46575/agrihumanis.v1i2.71

(c) 2020 oleh penulis. Diterbitkan di bawah lisensi Creative Commons Attribution 4.0 International (CC BY 4.0) 